\title{
A DFT Study on Deactivation of Triplet Excited State Riboflavin by Polyphenols
}

\section{Hong-Fang Ji and Liang Shen *}

Shandong Provincial Research Center for Bioinformatic Engineering and Technique, Center for Advanced Study, Shandong University of Technology, Zibo 255049, P.R. China

* Author to whom correspondence should be addressed; E-mail: shen@sdut.edu.cn

Received: 30 July 2008; in revised form: 7 September 2008 / Accepted: 27 September 2008 /

Published: 8 October 2008

\begin{abstract}
The deactivation of triplet excited state riboflavin by polyphenols, e.g. rutin and catechin, was studied on the basis of density functional theory calculations. The results show that the $\mathrm{H}$-atom transfer pathway is more feasible on thermodynamic grounds in comparison with the direct energy transfer or direct electron transfer pathways involved in the triplet excited state riboflavin deactivation by rutin/catechin. The findings are helpful to understand the protective effect of polyphenols against the riboflavin induced photosensitizing damage.
\end{abstract}

Keywords: Riboflavin, polyphenols, triplet excited state, deactivation, density functional theory.

\section{Introduction}

Numerous endogenous photosensitizers, among which riboflavin has attracted much attention, can photogenerate various reactive oxygen species (ROS, e.g. ${ }^{1} \mathrm{O}_{2}$ and $\mathrm{O}_{2}{ }^{-}$) $[1,2]$. It has been reported that riboflavin is an efficient ROS-generator [1, 3, 4] and can cause photosensitizing DNA damage [5, 6]. Polyphenolic compounds, e.g. rutin and catechin (Figure 1), are ideal antioxidants with strong free radical-scavenging ability. Recently, it was reported that rutin and catechin play dual roles in 
protecting from the photosensitizing damage caused by riboflavin, that is, as ROS scavengers and triplet excited $\left(\mathrm{T}_{1}\right)$ state riboflavin quenchers [7]. The free radical-scavenging mechanisms of rutin and catechin have been investigated before [8], however, more effort is needed to elucidate the deactivating mechanisms of $T_{1}$ state riboflavin by rutin/catechin. In recent years, density functional theory (DFT) calculations have been widely used to study both the photosensitization and deactivation mechanisms of excited state photosensitizers [4, 9-12]. Therefore, in the present study, we attempt to explore how $\mathrm{T}_{1}$ state riboflavin was deactivated by rutin/catechin by means of theoretical calculations.

Figure 1. Molecular structures of riboflavin, rutin and catechin.

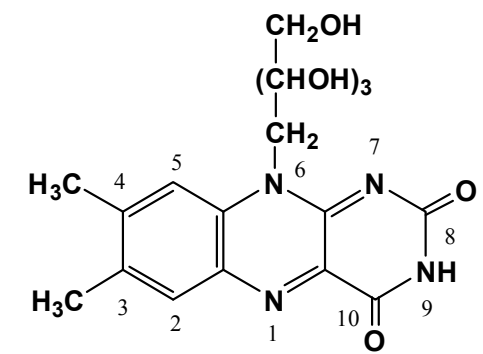

riboflavin

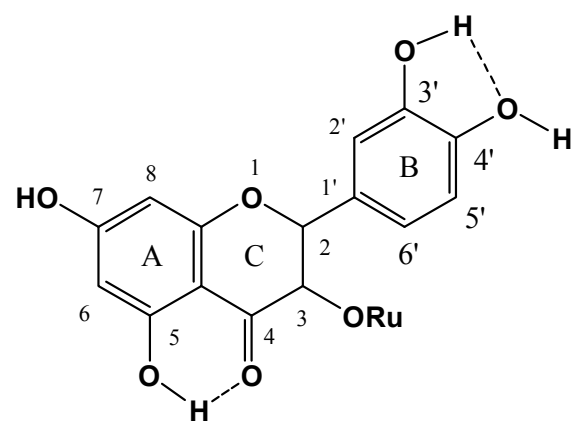

rutin $(\mathrm{Ru}=$ rutoside)<smiles>Oc1cc(O)c2c(c1)OC(c1ccc3c(c1)O[IH]O3)C(O)C2</smiles>

catechin

\section{Theoretical Methods}

The calculation procedures are as follows. First, the geometries of riboflavin, rutin and catechin were fully optimized by DFT [14, 15] and B3LYP functional [16-18] with 6-31G(d,p) Gaussian basis set in vacuo. Then, the lowest $\mathrm{T}_{1}$ excitation energies $\left(\mathrm{E}_{\mathrm{T} 1}\right)$ of the three molecules were estimated by time-dependent DFT (TD-DFT) [19-21] with the same basis set. Moreover, in view of the fact that the diffusion functions are crucial for treatment of anion and cation radicals, the vertical electron affinities (VEA) and vertical ionization potentials (VIP) of riboflavin, rutin and catechin were calculated by using a combined DFT method labeled as B3LYP/6-31+G(d,p)/B3LYP/6-31G(d,p), which means that B3LYP/6-31+G(d,p) was used to perform a single-point calculation using B3LYP/6-31G(d,p)optimized geometries [10]. The $\mathrm{O}-\mathrm{H}$ bond dissociation enthalpy (BDE) of rutin/catechin and $\mathrm{H}$-atom affinity (HAA) of riboflavin were obtained by a hybrid method combining DFT and semiempirical method AM1, labeled as (RO)B3LYP/6-311+G(2d,2p)/AM1, which takes advantages of accuracy and economy [8]. The solvent (benzene and water) effects were taken into account by employing the self- 
consistent reaction field (SCRF) method with polarizable continuum model (PCM) [22-24] for the single point calculations. All the calculations were accomplished using the Gaussian 03 package of programs [25].

\section{Results and Discussion}

As we know, the ground state photosensitizer is initially excited to the singlet excited state upon irradiation and then may intersystem cross to the relatively long-lived $T_{1}$ state. $T_{1}$ state riboflavin can react with molecular oxygen to photogenerate various ROS $[1,3,4]$ and at the same time, it can be deactivated by antioxidants through the following possible pathways:

The first deactivating pathway may proceed through the direct energy transfer between $\mathrm{T}_{1}$ state riboflavin (RF) and polyphenols (PhOH) (Equation 1).

$$
\mathrm{RF}\left(\mathrm{T}_{1}\right)+\mathrm{PhOH} \rightarrow \mathrm{RF}+\mathrm{PhOH}\left(\mathrm{T}_{1}\right)
$$

The second deactivating pathway involves the electron transfer between $\mathrm{T}_{1}$ state riboflavin and polyphenols (Equation 2).

$$
\mathrm{RF}\left(\mathrm{T}_{1}\right)+\mathrm{PhOH} \rightarrow \mathrm{RF}^{--}+\mathrm{PhOH}^{+}
$$

Moreover, as the polyphenolic antioxidants are ideal $\mathrm{H}$-atom donors [8], $\mathrm{T}_{1}$ state riboflavin may be deactivated by polyphenols through a $\mathrm{H}$-atom transfer process (Equation 3 ).

$$
\mathrm{RF}\left(\mathrm{T}_{1}\right)+\mathrm{PhOH} \rightarrow \mathrm{RFH}^{\cdot}+\mathrm{PhO} \cdot
$$

Therefore, the corresponding electronic parameters of riboflavin, rutin and catechin, including $\mathrm{E}_{\mathrm{T} 1}$, VEA, VIP, O-H BDE and HAA, were estimated and listed in Table 1, according to which, the deactivating reactions of $\mathrm{T}_{1}$ state riboflavin by rutin/catechin were analyzed.

Table 1. Theoretically estimated lowest triplet excitation energy $\left(\mathrm{E}_{\mathrm{T} 1}\right.$, in eV), vertical

\begin{tabular}{|c|c|c|c|c|c|}
\hline Compounds & Solvents & $\mathbf{E}_{\mathrm{T} 1}$ & VIP $_{\text {S0 }}$ & VEA $_{\mathbf{S}}$ & $\mathbf{V E A}_{\mathrm{T} 1}{ }^{\mathrm{a}}$ \\
\hline \multirow[t]{2}{*}{ Rutin } & benzene & 3.12 & 6.76 & & \\
\hline & water & 3.13 & 5.95 & & \\
\hline \multirow[t]{2}{*}{ Catechin } & benzene & 3.62 & 6.49 & & \\
\hline & water & 3.63 & 5.82 & & \\
\hline \multirow[t]{2}{*}{ Riboflavin $^{b}$} & benzene & 2.10 & & -2.52 & -4.62 \\
\hline & water & 2.09 & & -3.32 & -5.41 \\
\hline
\end{tabular}
electron affinity (VEA, in eV) and vertical ionization potential (VIP, in eV) of polyphenols (rutin and catechin) and riboflavin in benzene and water.

Primarily, the $\mathrm{E}_{\mathrm{T} 1}$ of riboflavin, rutin and catechin have been calculated using TD-DFT methods, whose accuracy in estimating the $T_{1}$ state properties of various photosensitizers has been verified [4, 913]. It can be seen that the theoretical $\mathrm{E}_{\mathrm{T} 1}$ of rutin/catechin is much higher than that of riboflavin 
(Table 1), implying that the direct energy transfer-based deactivating pathway (Equation 1) is not feasible on thermodynamic grounds in both solvents.

As to the direct electron transfer-based deactivating pathway (Equation 2), its feasibility depends on the VEA of $\mathrm{T}_{1}$ state riboflavin $\left(\mathrm{VEA}_{\mathrm{T} 1}\right)$ and VIP of rutin/catechin. According to the theoretical results, the summation of VEA $\mathrm{V}_{\mathrm{T} 1}$ of riboflavin and VIP of rutin/catechin is positive both in benzene and water, implying that the electron transfer-based deactivating pathway is also not favorable from the thermodynamic point of view.

Table 2. Theoretically estimated $\mathrm{O}-\mathrm{H}$ bond dissociation enthalpy (BDE, in $\mathrm{kcal} / \mathrm{mol}$ ) of the phenolic compounds (rutin and catechin) and $\mathrm{T}_{1}$ sate $\mathrm{H}$-atom affinity $\left(\mathrm{HAA}_{\mathrm{T} 1}\right.$, in $\mathrm{kcal} / \mathrm{mol}$ ) of riboflavin in benzene and water.

\begin{tabular}{cccc}
\hline Compounds & Solvents & O-H BDE & HAA $_{\mathbf{T 1}}{ }^{\mathrm{a}}$ \\
\hline \multirow{2}{*}{ Rutin } & benzene & 78.18 & \\
& water & 79.97 & \\
\cline { 2 - 4 } Catechin & benzene & 78.97 & \\
& water & 80.73 & \\
\cline { 2 - 3 } Riboflavin & benzene & -97.24 \\
& water & -106.19 \\
\hline \multicolumn{4}{c}{${ }^{\mathrm{a}} \mathrm{HAA}_{\mathrm{T} 1}=\mathrm{HAA}_{\mathrm{S} 0}+\mathrm{E}_{\mathrm{T} 1}}$. \\
\end{tabular}

Figure 2. Theoretically postulated H-atom transfer-based triplet excited state riboflavin deactivating pathway by rutin/catechin.

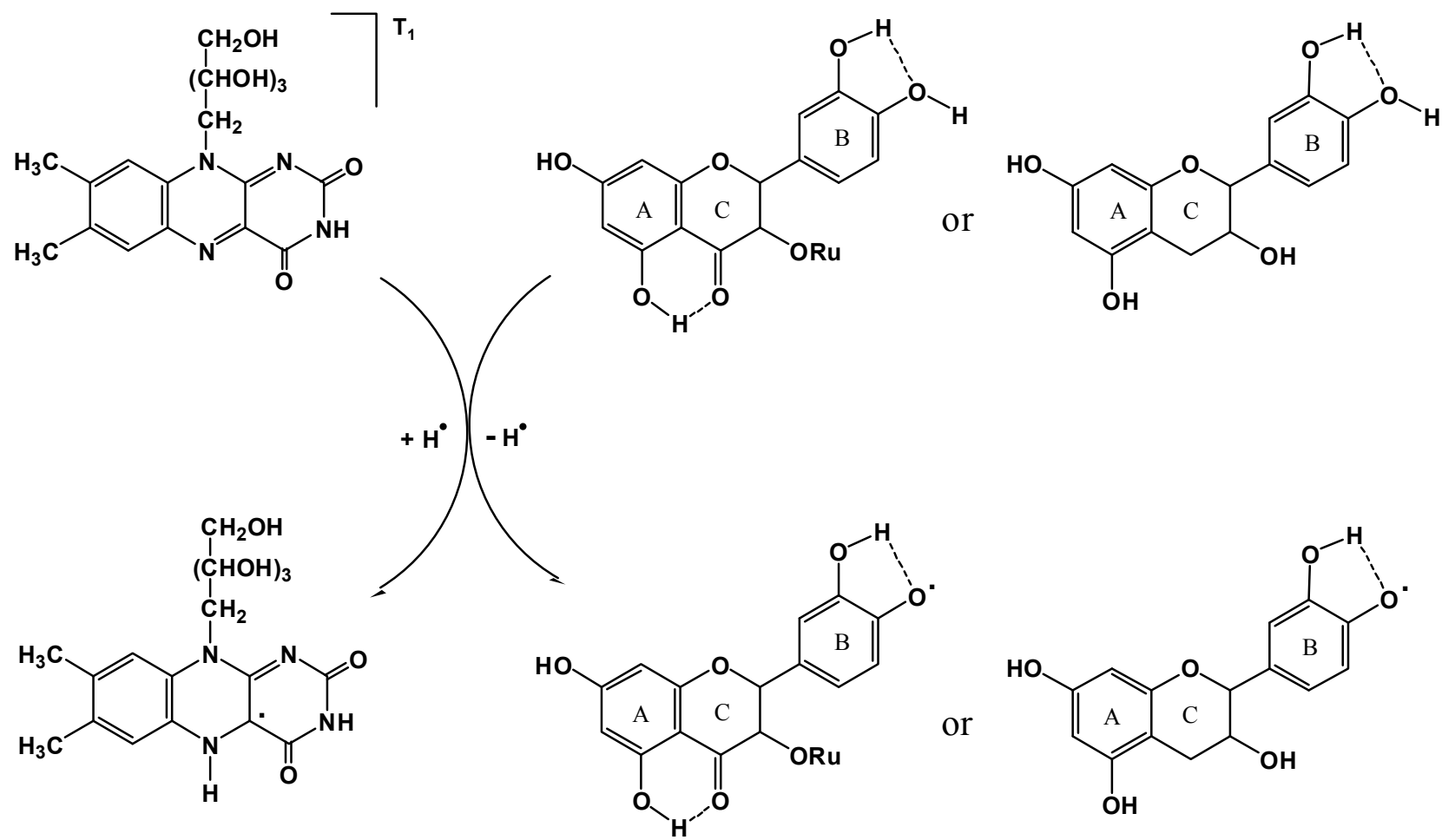


Thirdly, rutin and catechin are excellent $\mathrm{H}$-atom donating substrates [8]. To explore whether the $\mathrm{H}$ atom transfer reaction from rutin/catechin to $\mathrm{T}_{1}$ state riboflavin (Equation 3 ) can occur or not, the $\mathrm{O}-\mathrm{H}$ BDE of rutin and catechin, which has been successfully used to measure the molecular H-atomdonating ability [8], and the HAA of riboflavin, an appropriate theoretical parameter to characterize the molecular H-atom-abstracting ability [8], have been calculated. Despite the fact that rutin and catechin possess several phenolic hydroxyls that may donate $\mathrm{H}$-atoms, previous studies demonstrated that the hydroxyl at position 4' (Figure 1) is the most active one [26] and the corresponding O-H BDE in benzene and water is listed in Table 2 . The theoretically estimated HAA of $\mathrm{T}_{1}$ state riboflavin at N1 (Figure 1), which has been reported to be the thermodynamically favorable position to accept a $\mathrm{H}$ atom [27], is $-97.24 \mathrm{kcal} / \mathrm{mol}$ in benzene and $-106.19 \mathrm{kcal} / \mathrm{mol}$ in water (Table 2). As the summation of $\mathrm{HAA}_{\mathrm{T} 1}$ of riboflavin and the $\mathrm{O}-\mathrm{H} \mathrm{BDE}$ of rutin/catechin is negative in both solvents, the $\mathrm{H}$-atom transfer-based quenching pathway is thermodynamically feasible. Therefore, the H-atom transferbased $\mathrm{T}_{1}$ state riboflavin deactivating mechanism by rutin/catechin is proposed as illustrated in Figure 2.

\section{Conclusions}

In summary, through comparing the electronic parameters of riboflavin, rutin and catechin, including $\mathrm{E}_{\mathrm{T} 1}$, VEA, VIP, BDE and HAA, it can be inferred that the H-atom transfer pathway is more feasible on thermodynamic grounds relative to the direct energy transfer or direct electron transfer pathways responsible for the $T_{1}$ state riboflavin deactivation by rutin/catechin. The results have important implications to design/screen better polyphenolic antioxidants as protectors against the photo-oxidative damage induced by riboflavin.

\section{Acknowledgements}

This work was supported by the National Natural Science Foundation of China (Grant No. 30700113) and the Natural Science Foundation of Shandong Province (Grant No. Y2007D53).

\section{References and Notes}

1. Baier, J.; Maisch, T.; Maier, M.; Engel, E.; Landthaler, M.; Bäumler, W. Singlet oxygen generation by UVA light exposure of endogenous photosensitizers. Biophys. J. 2006, 91, 1452-1459.

2. Wondrak, G.T.; Jacobson, M.K.; Jacobson, E.L. Endogenous UVA-photosensitizers: Mediators of skin photodamage and novel targets for skin photoprotection. Photochem. Photobiol. Sci. 2006, 5, 215-237.

3. Grzelak, A.; Rychlik, B.; Bartosz, G. Light-dependent generation of reactive oxygen species in cell culture media. Free Radic. Biol. Med. 2001, 30, 1418-1425.

4. Shen, L.; Ji, H.F.; Zhang, H.Y. Computational note on the photosensitization mechanisms of riboflavin. J. Mol. Struct. (Theochem) 2007, 821, 171-172. 
5. Ito, K.; Inoue, S.; Yamamoto, K.; Kawanishi, S. 8-Hydroxydeoxyguanosine formation at the 5' site of 5'-GG-3' sequences in double-stranded DNA by UV radiation with riboflavin. J. Biol. Chem. 1993, 268, 13221-13227.

6. Joshi, P.C. Comparison of the DNA-damaging property of photosensitised riboflavin via singlet oxygen $\left({ }^{1} \mathrm{O}_{2}\right)$ and superoxide radical $\mathrm{O}^{2-\cdot}$ mechanisms. Toxicol. Lett. 1985, 26, 211-217.

7. Becker, E.M.; Cardoso, D.R.; Skibsted, L.H. Deactivation of riboflavin triplet-excited state by phenolic antioxidants: mechanism behind protective effects in photooxidation of milk-based beverages. Eur. Food. Res. Technol. 2005, 221, 382-386.

8. Zhang, H.Y. Structure-activity relationships and rational design strategies for radical-scavenging antioxidants. Curr. Computer-Aided Drug Des. 2005, 1, 257-273.

9. Shen, L.; Ji, H.F.; Zhang, H.Y. A theoretical elucidation on the solvent-dependent photosensitive behaviors of $\mathrm{C}_{60}$. Photochem. Photobiol. 2006, 82, 798-800.

10. Shen, L.; Ji, H.F.; Zhang, H.Y. A TD-DFT study on triplet excited-state properties of curcumin and its implications in elucidating the photosensitizing mechanisms of the pigment. Chem. Phys. Lett. 2005, 409, 300-303.

11. Shen, L.; Ji, H.F.; Zhang, H.Y. Hypericin anion is crucial to elucidating the pigment's photosensitive features. Bioorg. Med. Chem. Lett. 2006, 16, 1414-1417.

12. Shen, L.; Ji, H.F. How $\alpha$-tocopherol quenches triplet state riboflavin? Insights from theory. $J$. Photochem. Photobiol. A: Chem. 2008, 199, 119-121.

13. Shen, L.; Ji, H.F. A theoretical study on the quenching mechanisms of triplet state riboflavin by tryptophan and tyrosine. J. Photochem. Photobiol. B: Biol. 2008, 92, 10-12.

14. Hohenberg, P.; Kohn, W. Inhomogeneous electron gas. Phys. Rev. 1964, 136, B864-B871.

15. Kohn, W.; Sham, L.J. Self-consistent equations including exchange and correlation effects. Phys. Rev. 1965, 140, A1133-A1138.

16. Lee, C.; Yang, W.; Parr, R.G. Development of the Colle-Salvetti correlation energy formula into a functional of the electron density. Phys. Rev. B. 1988, 37, 785-789.

17. Becke, A.D. A new mixing of Hartree-Fock and local density-functional theories. J. Chem. Phys. 1993, 98, 1372-1377.

18. Stephens, P.J.; Devlin, F.J.; Chabalowski, C.F.; Frisch, M.J. Ab Initio calculation of vibrational absorption and circular dichroism spectra using density functional force fields. J. Phys. Chem. 1994, 98, 11623-11627.

19. Stratmann, R.E.; Scuseria, G.E.; Frisch, M.J. An efficient implementation of time-dependent density-functional theory for the calculation of excitation energies of large molecules. $J$. Chem. Phys. 1998, 109, 8218-8224.

20. Bauernschmitt, R.; Ahlrichs, R. Treatment of electronic excitations within the adiabatic approximation of time dependent density functional theory. Chem. Phys. Lett. 1996, 256, 454-464.

21. Casida, M.E.; Jamorski, C.; Casida, K.C.; Salahub, D.R. Molecular excitation energies to highlying bound states from time-dependent density-functional response theory: Characterization and correction of the time-dependent local density approximation ionization threshold. J. Chem. Phys. 1998, 108, 4439-4449. 
22. Miertus, S.; Scrocco, E.; Tomasi, J. Electrostatic interaction of a solute with a continuum. A direct utilization of ab initio molecular potentials for the prevision of solvent effects. Chem. Phys. 1981, $55,117-129$.

23. Miertus, S.; Tomasi, J. Approximate evaluations of the electrostatic free energy and internal energy changes in solution processes. Chem. Phys. 1982, 65, 239-241.

24. Cossi, M.; Barone, V.; Cammi, J. Ab initio study of solvated molecules: a new implementation of the polarizable continuum model. Chem. Phys. Lett. 1996, 255, 327-335.

25. Frisch, M.J.; Trucks, G.W.; Schlegel, H.B.; Scuseria, G.E.; Robb, M.A.; Cheeseman, J.R.; Montgomery, J.A.; Vreven, T.; Kudin, K.N.; Burant, J.C. et al. Gaussian 03; Gaussian, Inc.: Pittsburgh PA, 2003.

26. Pannala, S.A.; Chan, T.S.; O'Brien, P.J.; Rice-Evans, C.A. Flavonoid B-ring chemistry and antioxidant activity: fast reaction kinetics. Biochem. Biophys. Res. Commun. 2001, 282, 1161-1168.

27. Cardoso, D.R.; Olsen, K.; Skibsted, L.H. Mechanism of deactivation of triplet-excited riboflavin by ascorbate, carotenoids, and tocopherols in homogeneous and heterogeneous aqueous food model systems. J. Agric. Food Chem. 2007, 55, 6285-6291.

(C) 2008 by the authors; licensee Molecular Diversity Preservation International, Basel, Switzerland. This article is an open-access article distributed under the terms and conditions of the Creative Commons Attribution license (http://creativecommons.org/licenses/by/3.0/). 